\title{
Influence of grain size, solute atoms and second-phase particles on creep behavior of polycrystalline solids
}

\author{
Oleg D. Sherby ${ }^{a, *}$, Eric M. Taleff ${ }^{b}$ \\ ${ }^{a}$ Department of Materials Science and Engineering, Stanford University, Stanford, CA 94305, USA \\ ${ }^{\mathrm{b}}$ Department of Mechanical Engineering, The University of Texas at Austin, Texas Materials Institute, Austin, TX 78712, USA
}

\begin{abstract}
Diffusion-controlled-creep processes are used to assess the creep behavior of dispersion and solute hardened materials at coarse and fine grain sizes. It is shown that the creep behavior of a dispersion strengthened (DS) $\mathrm{Al}-\mathrm{Mg}$ alloy is similar to the creep behavior of pure $\mathrm{Al}-\mathrm{Mg}$ alloys. Both materials show dislocation climb and dislocation solute-drag contributions to creep. It is shown that the threshold stress for creep for these materials is a function of the mobile dislocation density, of the dislocation velocity and of the concentration of solute atoms in the dislocation core. It is, therefore, appropriate to describe the threshold stress as the threshold strain rate. It is shown that the same value of the diffusion-compensated strain rate for the threshold stress is obtained for slip in $\mathrm{DS} \mathrm{Al}-\mathrm{Mg}$ material as in a fine-grained $\mathrm{Al}-\mathrm{Mg}$ alloy, where grain-boundary sliding is the principal deformation process. This is evidence that grain boundary sliding is accommodated by dislocation creep. (C) 2002 Elsevier Science B.V. All rights reserved.
\end{abstract}

Keywords: Creep; Solute effects; Grain-size effects; Threshold stress

\section{Introduction}

This paper is written in memory and honor of John Dorn, who was a mentor to one of the present authors (ODS). It is presented as a sequel to the conference proceedings on creep held at the October 1972 meeting in Cleveland, $\mathrm{OH}$ and published by the American Society of Metals in 1975 [1]. The ground work on understanding creep behavior of materials and on creep mechanisms was well established by that time [2-4]. In subsequent years, however, as more complex metals, alloys and metal-and-ceramic based compounds were studied for their creep behavior, much new knowledge has evolved. This paper will center on some specific aspects of these more recent studies.

The creep process in polycrystalline solids is controlled by, or involved with, one of three mechanisms. These are diffusion-controlled dislocation creep, grainboundary sliding and diffusional creep. The first part of this paper will center on materials where dislocation

\footnotetext{
* Corresponding author. Tel.: + 1-415-7252636; fax: + 1-4157254034.

E-mail address: bulatole@aol.com (O.D. Sherby).
}

creep is the dominant mechanism. The second part will center on materials where grain-boundary sliding is considered to be the dominant mechanism and where superplasticity is observed. Diffusional creep will not be covered, since debate on this subject was described in a recent conference proceedings [5].

\section{Diffusion-controlled dislocation creep}

Most coarse-grained polycrystalline solids deform by diffusion-controlled dislocation creep. The diffusion coefficient is typically the lattice diffusion coefficient if creep tests are performed above one-half the absolute melting temperature. These materials are generally viewed as following a power-law relation, where the creep rate, $\dot{\varepsilon}$, is proportional to the stress, $\sigma$, following the relation, $\dot{\varepsilon} \propto \sigma^{n}$, where $n$ is the stress exponent. When the stress exponent is one, it is considered to be Harper-Dorn (H-D) creep where dislocations move through a uniform sea of stationary dislocations, whose density is invariant with stress [6]. Theories and postulates for $\mathrm{H}-\mathrm{D}$ creep have been presented by Mohamed and Ginter [7], Wu and Sherby [8] and Wang [9]. Blum 
and Maier [10] have suggested that H-D creep has not been verified and does not exist when experiments are performed more accurately. It is, however, difficult to reject the extensive evidence for this creep process [11]. When the stress exponent is three, it is considered to be that of dislocation glide controlled by the rate of migration of solute atom atmospheres that are attached to the moving dislocations (Class I solid solution alloys). The theory for solute-drag creep has been well developed by Weertman [12]. When the stress exponent is five, it is believed to be dislocation climb-controlled and is observed in materials that develop subgrains. This conclusion is confirmed by extensive experimental evidence [2-4] and by Weertman's dislocation-climb theory [13]. These subgrain-forming materials exhibit power-law breakdown (PLB) at a common value of the lattice diffusion-compensated creep rate of $\approx 10^{13} \mathrm{~m}^{-2}$ [14]. The occurrence of PLB has been attributed to excess vacancy generation at stresses above PLB [14]. On the other hand, Raj [15] among others has suggested an alternative explanation based on non-diffusion controlled processes, such as cross-slip or obstacle-controlled glide. When the stress exponent is eight, it is believed to be dislocation-climb creep, the same as for five-power-law creep, but under constant structure conditions. Experimental confirmation for this creep exponent arises from stress change tests [16], from creep behavior of dispersion hardened materials $[17,18]$ and from materials where no subgrains form during

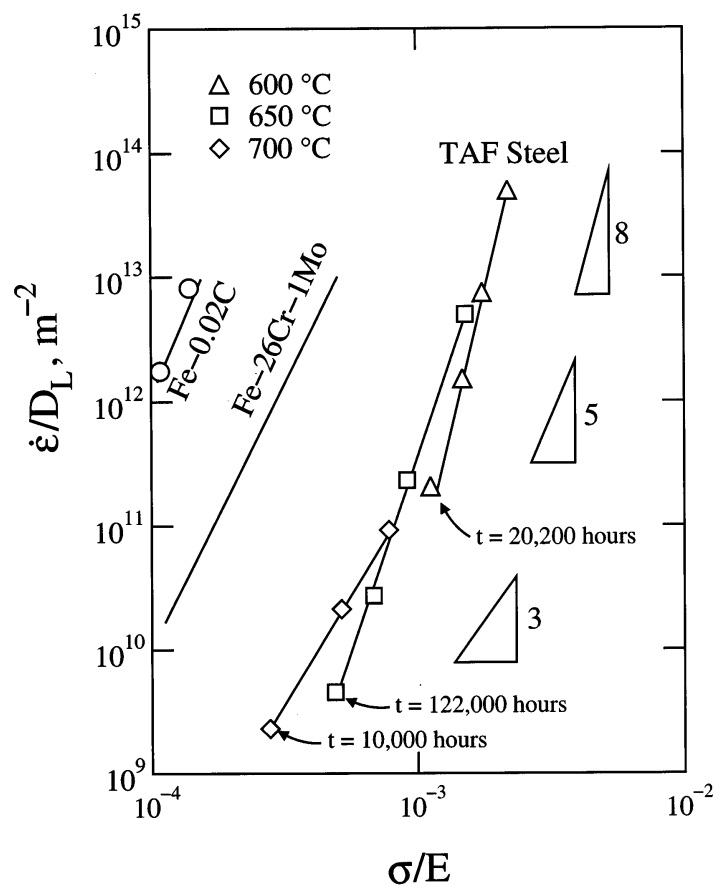

Fig. 1. The data of Fujita [20] for TAF steel are plotted with data from $\mathrm{Fe}-26 \mathrm{Cr}-1 \mathrm{Mo}$ [24] and $\mathrm{Fe}-0.02 \mathrm{C}$ [2] as lattice-diffusion-compensated creep rate versus modulus-compensated stress on logarithmic scales. creep $[14,19]$. Power law breakdown is often not observed, even up to lattice diffusion-compensated strain rates as high as $10^{17} \mathrm{~m}^{2} \mathrm{~s}^{-1}$.

There are material systems that do not fit the powerlaw relations described above and sometimes do not appear to be lattice-diffusion controlled. Such material systems can be divided into two groups. One group is related to materials used in high temperature creep-limited applications, such as in power plants and aerospace engines. Another group of materials is the so-called advanced composite materials. The latter group is materials that contain fibers and particles for strengthening and are processed by mechanical alloying and powder metallurgy methods. The present authors believe that almost all of the above cases involve materials where solid solution alloying plays an important role in strengthening the matrix and possibly in rate-controlling the creep process. It is the purpose of this section of the paper to consider the influence of solute atoms on the creep behavior of these two groups of materials.

Fujita [20] has recently reviewed the types of materials to be used in future power plants. The objective is to develop stronger heat resistant steels to improve efficiency in coal-fired power generating plants. The current effort involves $9-11 \% \mathrm{Cr}$ ferritic steels. One of the goals is to achieve strengths of $100 \mathrm{MPa}$ for $100000 \mathrm{~h}$ rupture life at $650^{\circ} \mathrm{C}$. A number of candidate materials are being evaluated for their stress-rupture life where tests to $100000 \mathrm{~h}$ (over 11 years) are required. Stressrupture data for one of these developmental steels, designated as TAF steel, are given in the Fujita publication. Its composition is, in weight percent: $0.18 \mathrm{C}, 0.5 \mathrm{Si}$, $1.0 \mathrm{Mn}, 10.5 \mathrm{Cr}, 1.5 \mathrm{Mo}, 0.2 \mathrm{~V}, 0.15 \mathrm{Nb}, 0.020 \mathrm{~N}, 0.04 \mathrm{~B}$ and balance $\mathrm{Fe}$. All alloying elements are intentional additions to achieve optimal mechanical and chemical properties. TAF steel was developed by Fujita et al. in 1952, and now, almost a half century later, it is being evaluated as a potential candidate material for advanced power systems. The present authors considered that the TAF material would be a good material to evaluate from the viewpoint of lattice-diffusion-controlled power-law creep. Fig. 1 illustrates Fujita's data plotted as lattice-diffusion-compensated creep rate, $\dot{\varepsilon} /$ $D_{\mathrm{L}}$, as a function of the elastic modulus compensated stress, $\sigma / E$. The creep rate was calculated by means of the Monkman-Grant relation [21], with $\dot{\varepsilon}=0.2 / t_{\mathrm{r}}$, where $t_{\mathrm{r}}$ is the time to rupture. The value of 0.2 is the typical fracture strain observed in the TAF material at all temperatures. The lattice self-diffusion of iron, $D_{\mathrm{L}}$, was used from the compilation of Oikawa [22] and the elastic (dynamic, unrelaxed, polycrystalline) modulus was from the work of Köster [23].

The correlation shown in Fig. 1 does show the desired effect of bringing the data from TAF steel toward a common curve. The data for each of the three tem- 


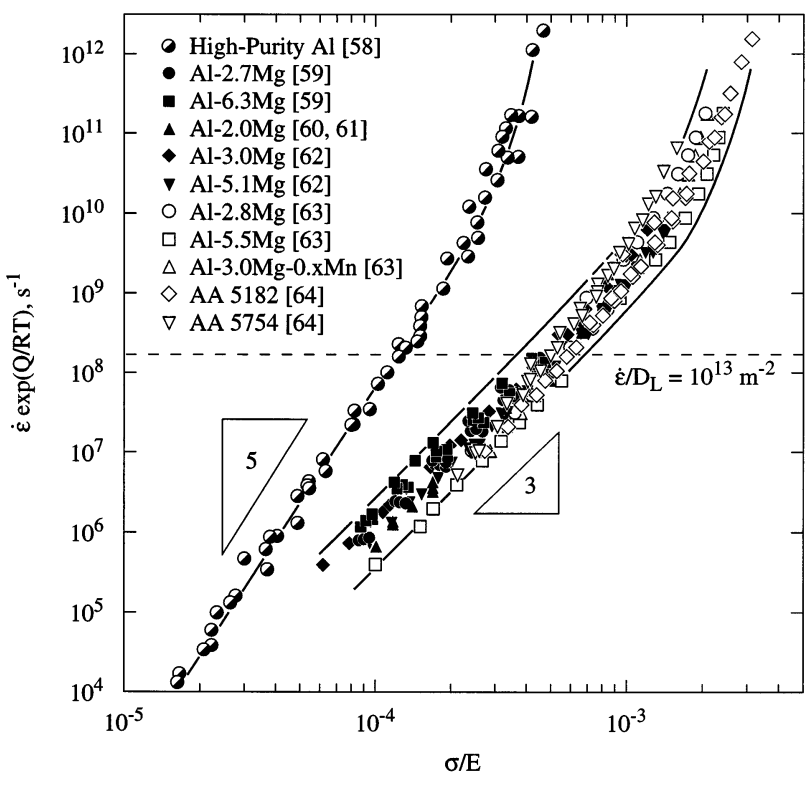

Fig. 2. Data of high-purity aluminum [58] and numerous aluminum alloys containing magnesium [59-64] are plotted as the Zener-Hollomon parameter versus modulus-compensated stress on logarithmic scales.

peratures, however, do not superimpose perfectly, as is observed in pure metals. This indicates that the temperature compensation through $D_{\mathrm{L}}$ and $E$ was not sufficient to make a good fit of the data. On the other hand, one can create some form of order based on the observed stress exponents. The stress exponents for the TAF steel are those observed for metals and alloys, that is, three, five and eight. Thus, one might conclude that the low temperature data $\left(600^{\circ} \mathrm{C}\right)$ with a stress exponent of eight, might represent creep under constant structure conditions where the structure is maintained constant by the presence of stable precipitates within a matrix of iron containing a number of elements in solution. The stress exponent at intermediate temperature $\left(650^{\circ} \mathrm{C}\right)$ is about five. This stress exponent can be identified with creep processes where strain-created subgrains form, increasing in size with decreasing stress. This result can be expected if the majority of precipitates present at $600^{\circ} \mathrm{C}$ have dissolved at $650^{\circ} \mathrm{C}$. The strength of the TAF material in the $n=5$ range is compared with pure iron [2] and with a $\mathrm{Fe}-26 \mathrm{Cr}-1 \mathrm{Mo}$ [24] steel in Fig. 1. The differences in strength are likely a result of stacking fault energy differences from the solute elements $\mathrm{Cr}, \mathrm{Mo}, \mathrm{V}, \mathrm{Nb}$ and $\mathrm{Si}$, including synergistic effects from these elements and carbon.

The stress exponent at high temperature $\left(700^{\circ} \mathrm{C}\right)$ for the TAF material is equal to about three. It is probable that solute-drag dislocation creep is controlling the deformation process in this range. Data are needed on solute diffusion of the various elements in the TAF steel at $700^{\circ} \mathrm{C}$ to make a definitive statement on the element or elements creating solute-drag creep. How- ever, the solute elements most likely to create solutedrag creep in $\mathrm{Fe}$, based on atomic misfit strains, are $\mathrm{Mo}, \mathrm{Nb}$ and $\mathrm{V}$, in that order. This behavior is not likely attributed to the element $\mathrm{Cr}$, since there is no hint of such influence in pure iron-chromium alloys.

The obvious conclusion in the above interpretation of data is that the microstructure influencing creep is different at each temperature. Therefore, a simple universal relation for the creep behavior of this typical ferritic power-plant steel is not readily achieved at all temperatures. Although the interpretation of creep data presented above may require revision as more information on the TAF material becomes available, it points toward the need of further investigations into the interconnection of temperatures, times and stresses with the corresponding microstructures present during creep.

The creep behavior of TAF steel (Fig. 1) involves a large number of alloying elements and it is difficult and currently impossible, to separate out the contribution of each element to the creep process. In the following section, creep data will be illustrated in material systems where the compositions are relatively simple, with emphasis on metal systems that contain solute atoms. It will be shown that, even in these simpler alloy systems, interesting complications arise. However, a pattern of order still exists. Because of this order, predictive relations can and are being developed.

\subsection{Creep of Class I solid solution alloys}

Fig. 2 is a graph of the Zener-Hollomon parameter as a function of the modulus-compensated stress for a number of $\mathrm{Al}-\mathrm{Mg}$ solid solution alloys and for pure aluminum [25]. The Zener-Hollomon parameter is given as $\mathrm{Z}=\dot{\varepsilon} \exp (Q / R T)$, where $Q$ was selected as the activation energy for self-diffusion of aluminum $(Q=$ $142 \mathrm{~kJ} \mathrm{~mol}^{-1}$ ). The $\mathrm{Al}-\mathrm{Mg}$ alloys show a stress exponent of about three over a wide range of stress and power-law breakdown (PLB) is observed at high stresses. This is typical of Class I solid solution behavior [2]. The pure aluminum data show a stress-exponent of about 5 with PLB occurring at about the same value of diffusion-compensated creep rate of $10^{13} \mathrm{~m}^{-2}$ observed for the $\mathrm{Al}-\mathrm{Mg}$ solid solution alloys. A horizontal line is drawn in Fig. 2 showing where $\dot{\varepsilon} / D_{\mathrm{L}}$ is equal to $10^{13} \mathrm{~m}^{-2}$. The selection of an activation energy of $142 \mathrm{~kJ} \mathrm{~mol}^{-1}$ is justified since the diffusivity and activation energy for solute diffusion of magnesium in aluminum $\left(Q_{\text {solute }}=136 \mathrm{~kJ} \mathrm{~mol}^{-1}\right)$ are nearly the same as for aluminum in aluminum [25].

Oikawa et al. [26] have shown that when $\mathrm{Al}-\mathrm{Mg}$ alloys are tested at yet lower stresses, below $\sigma / E=$ $10^{-4}$, the stress exponent becomes equal to five. This change in stress exponent is in agreement with the concept that dislocation climb has replaced solute-drag creep with a decrease in stress. This occurs because the 
two processes, viscous dislocation glide and dislocation climb, are sequential and, therefore, interdependent. Thus, the slowest process is rate-controlling. In the five-power-law region at low stresses, the $\mathrm{Al}-\mathrm{Mg}$ alloys are about a factor of two and a half stronger than pure aluminum [27]. This strength increase must be attributed to a matrix solute strengthening effect, as was discussed with the iron and iron-chromium-molybdenum alloys (Fig. 1), for which strengthening arises from a stacking-fault-energy effect. On the other hand, in the



Fig. 3. The stress exponents of various $\mathrm{Al}-\mathrm{Mg}$ solid solution alloys containing ternary additions of $\mathrm{Mn}, \mathrm{Fe}$ or $\mathrm{Zn}$ are plotted as a function of $\mathrm{Mg}$ content [25].

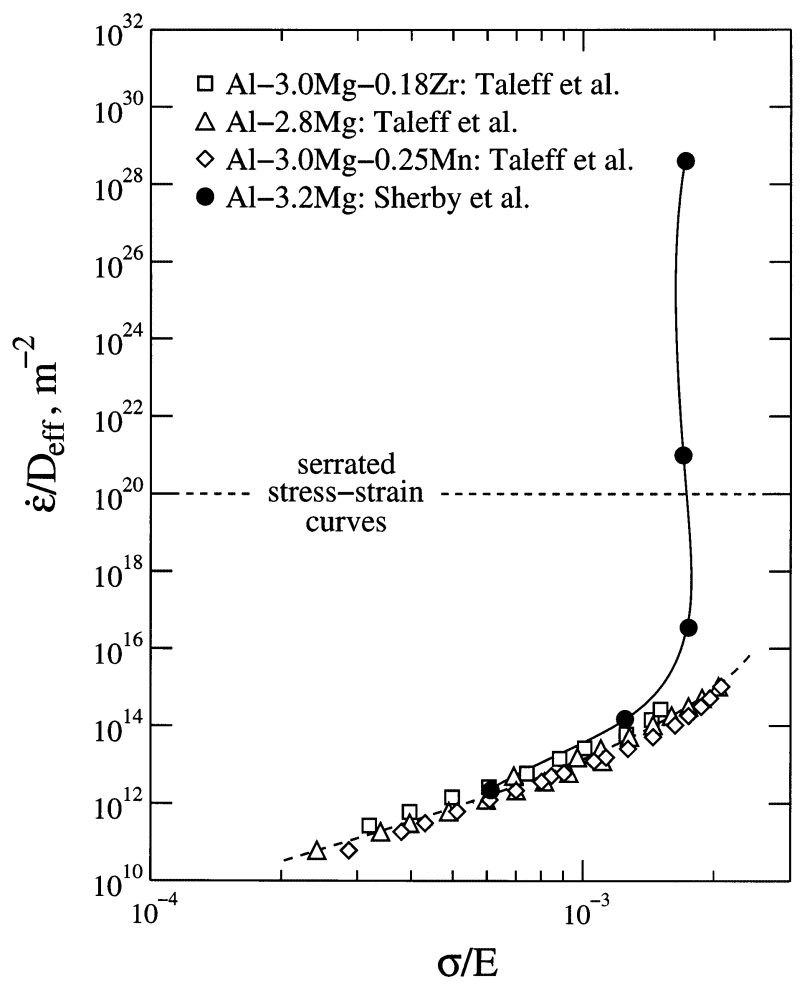

Fig. 4. The low-temperature data of an $\mathrm{Al}-3 \mathrm{Mg}$ alloy [32], at $\varepsilon=0.05$ strain, are plotted with high-temperature data from similar alloys [63] as creep rate accommodated by effective diffusivity as a function of modulus-compensated stress. solute-drag-creep region, the strength of $\mathrm{Al}-\mathrm{Mg}$ alloys is independent of magnesium content $(2-10 \% \mathrm{Mg})$. This is attributed by McNelley et al. [28] to the saturation effect of magnesium atoms (above $\approx 2 \%$ magnesium) in the core of the moving dislocation. Mills et al. [29] have shown that the dislocation density in the $n=3$ range follows the Taylor relation, with the dislocation density increasing with stress to the second power.

If one applies the knowledge gained from the creep behavior of the $\mathrm{Al}-\mathrm{Mg}$ alloys to the creep of the TAF steel (Fig. 1), a specific prediction can be made. That is, one can expect that the stress exponent will change from three to five for the $700^{\circ} \mathrm{C}$ data at stresses below $2 \times 10^{-4} E$. This prediction would give a more optimistic prediction of the creep-rupture life of TAF at low stresses than an extrapolation with $n=3$. This type of trend in heat resistant steels, in fact, is seen with a $0.5 \%$ Mo steel, known as JIS STBA 12, reported by Kimura et al. [30].

Taleff et al. [25] have studied the effect of dilute alloying additions on the stress exponent for $\mathrm{Al}-\mathrm{Mg}$ alloys. Their results are shown in Fig. 3. This study was directed towards developing quasi-superplastic properties (i.e. highly rate-sensitive coarse-grained aluminum alloys) with superior room temperature properties. As can be seen, manganese increases the stress exponent at constant magnesium content. This was attributed to the presence of $\mathrm{Al}_{6} \mathrm{Mn}$ precipitates. A similar trend is noted for iron additions (where $\mathrm{Al}_{3} \mathrm{Fe}$ precipitates are present), although the stress exponent is not increased as much as in the case of manganese additions. The stress exponent of $\mathrm{Al}-\mathrm{Mg}$ alloys with a large amount of zinc, $\approx 5 \mathrm{wt} . \%$, is seen to decrease with an increase in magnesium content. The same stress exponent observed in pure $\mathrm{Al}-\mathrm{Mg}$ is predicted for the $\mathrm{Al}-5 \mathrm{Zn}$ alloy at $\approx 5 \% \mathrm{Mg}$. The addition of zinc permits achieving high strengths at room temperature after heat-treatment for precipitation hardening. Thus, $\mathrm{Al}-\mathrm{Mg}-5 \mathrm{Zn}$ alloys are predicted to be quasi-superplastic at $350^{\circ} \mathrm{C}$ and strong at room temperature.

The creep behavior of the $\mathrm{Al}-\mathrm{Mg}$ solid solution alloys becomes more complicated when the temperature of testing is below about one-half of the absolute melting temperature. This is shown in Fig. 4, where the creep rate is normalized by the effective diffusion coefficient, $D_{\text {eff }}$, as a function of the modulus-compensated stress. $D_{\text {eff }}$ incorporates the additive contributions of lattice diffusion and dislocation-short circuit diffusion to the creep process $[19,31]$. Fig. 4 shows that the stress exponent for an $\mathrm{Al}-\mathrm{Mg}$ solid solution alloy approaches infinity at low temperatures. In the same temperature range, the activation energy for creep also approaches infinity [32]. The nearly vertical line, then, can be considered as the threshold stress for creep of the pure $\mathrm{Al}-3.2 \mathrm{Mg}$ alloy. It is the region where the flow stress (at $\varepsilon=0.05$ ) is independent of temperature. The 


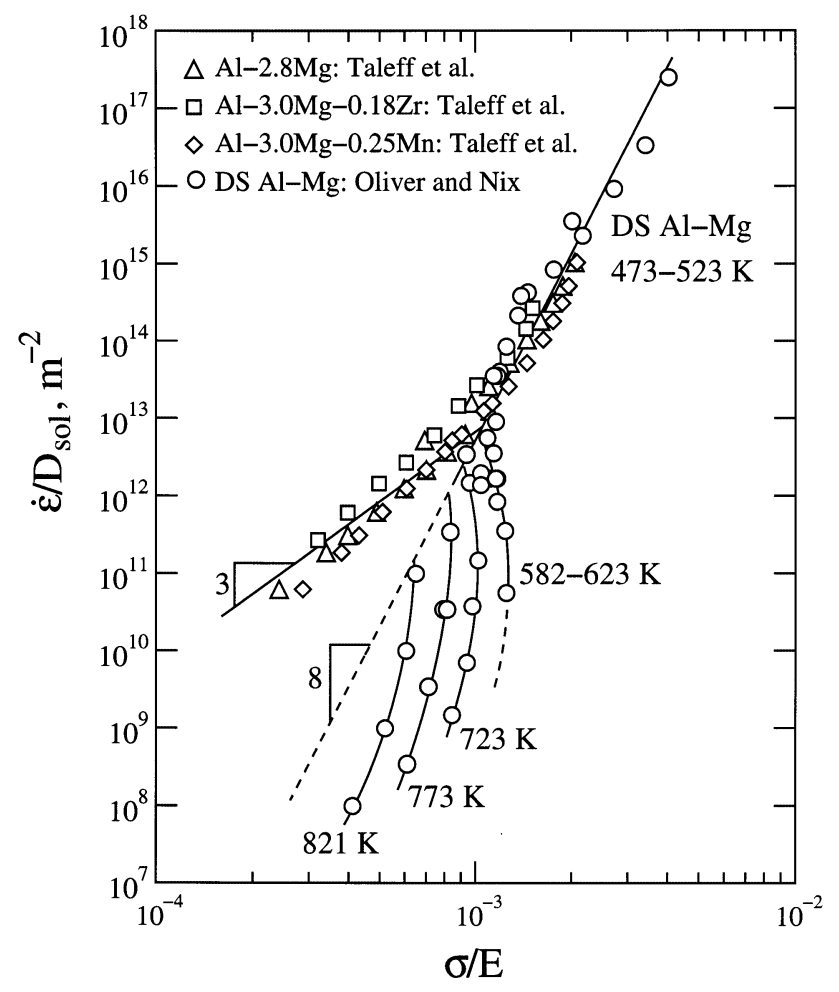

Fig. 5. The data of Oliver and Nix [27] for DS Al-Mg are presented with data from other $\mathrm{Al}-\mathrm{Mg}$ alloys processed by standard metallurgy techniques. Data are given as the diffusivity-compensated creep rate as a function of modulus-compensated stress.

threshold stress increases with an increase in solute content and with an increase in strain rate $[1,33]$. It is well accepted that this region represents creep controlled by the interaction of solute atmospheres with moving dislocations to such a level that an athermaltype trend is achieved. This interaction leads to an inverse-strain-rate effect, that is, the flow stress decreases with an increase in strain rate. In this region, stress-strain curves show continuous serrations, well known as the Portevin-Le Chatelier effect. For the $\mathrm{Al}-3.2 \mathrm{Mg}$ material, serrated stress-strain curves appear at $\dot{\varepsilon} / D_{\text {eff }}$ equal to $\approx 1 \times 10^{20} \mathrm{~m}^{-2}$. At a strain rate of $2 \times 10^{-3} \mathrm{~s}^{-1}$, it occurs at $20^{\circ} \mathrm{C}\left(0.31 T_{\mathrm{m}}\right)$.

Oliver and Nix [27] studied the creep behavior of an $\mathrm{Al}-\mathrm{Mg}$ alloy processed by a powder metallurgy and mechanical alloying route, followed by hot extrusion. This material (IN9051) was prepared and processed by the International Nickel Company. The processing resulted in a material containing dispersoids of $\mathrm{MgO}$ and $\mathrm{Al}_{4} \mathrm{C}_{3}$ and the matrix containing at least $2.1 \% \mathrm{Mg}$ in solution [27]. The presence of these dispersoids plays an important role in the creep behavior of the DS Al- Mg material. This is because most of the dislocations are pinned by the particles, leading to a very low mobile dislocation density. The TEM work of Hasegawa et al. [34] gives convincing evidence for this view. Fig. 5 compares the steady-state creep behavior of the DS
$\mathrm{Al}-\mathrm{Mg}$ material with the $\mathrm{Al}-\mathrm{Mg}$ alloys, described earlier (Fig. 3). The temperature range of creep testing is given adjoining each curve. A dramatic difference in creep behavior is to be noted between the DS Al-Mg and the pure $\mathrm{Al}-\mathrm{Mg}$ alloys. The principal observations are:

1. The DS $\mathrm{Al}-\mathrm{Mg}$ material is weaker than the pure $\mathrm{Al}-\mathrm{Mg}$ alloys at low temperatures, 473-623 K $\left(0.51-0.67 T_{\mathrm{m}}\right)$ and high stresses. Oliver and Nix concluded that this meant the rate-controlling process in this range was not solute-drag but dislocation-climb-controlled creep. Sherby et al. [35] concurred with this conclusion and drew a straight line through the Oliver-Nix data with a slope of eight. This slope was justified by assuming that the structure was invariant with stress since the fine particles of $\mathrm{MgO}$ and $\mathrm{Al}_{4} \mathrm{C}_{3}$ would be the principal barriers to plastic flow.

2. The $\mathrm{DS} \mathrm{Al}-\mathrm{Mg}$ material is very much stronger than the pure $\mathrm{Al}-\mathrm{Mg}$ alloys at high temperatures, 623$821 \mathrm{~K}\left(0.67-0.89 T_{\mathrm{m}}\right)$ and low stresses. Furthermore, it is even stronger than the extrapolated strength of the constant structure $(n=8)$ DS Al$\mathrm{Mg}$ material tested at low stresses (dashed line in Fig. 5).

The results for the DS Al- $\mathrm{Mg}$ are characteristic of most dispersion-strengthened aluminum alloys. Threshold-stress-type behavior is noted in these systems [36]. The temperature dependence of the threshold stress for the DS $\mathrm{Al}-\mathrm{Mg}$ material can be explained by the same mechanism as described earlier for the pure $\mathrm{Al}-\mathrm{Mg}$ alloys at low temperatures. It is proposed that the temperature dependence is related to the concentration of magnesium atoms at the dislocation site (Cottrell atmosphere). The concentration of solute, which dictates the interaction force between solute and dislocation, will decrease with an increase in temperature. It is an evaporation effect. The thermodynamics of this relation has been described by Cahn [37]. Eventually, at high enough temperature, when the solute concentration is the same at the dislocation site as in the matrix, then normal diffusion-controlled dislocation-climb creep can be expected.

The details of a complete explanation for the creep behavior of the $\mathrm{DS} \mathrm{Al}-\mathrm{Mg}$ material require better understanding of migrating solute atoms and mobile dislocation densities and velocities. Most creep studies on dispersion-hardened materials report minimum or steady-state creep rates as a function of stress and temperature. In recent years, it has become clear that the creep strain is also a major variable $[38,47]$. The creep rate changes with straining, and this is the result of changing microstructure and changing creep mechanisms. Oliver and Nix [27] were among the first to show flow stress curves as a function of strain at different strain rates and different temperatures in complex metal 
systems (i.e. DS $\mathrm{Al}-\mathrm{Mg}$ ). It will be shown that the DS $\mathrm{Al}-\mathrm{Mg}$ shows characteristics that are directly related to those observed in pure Class I solid solution alloys.

Fig. 6 shows stress-strain curves for DS $\mathrm{Al}-\mathrm{Mg}$ at several strain rates at two temperatures, $582 \mathrm{~K}(0.62$ $\left.T_{\mathrm{m}}\right)$ and $773 \mathrm{~K}\left(0.83 T_{\mathrm{m}}\right)$. Strain softening is observed at high stresses and strain hardening is observed at low stresses. The change-over in this trend occurs at a

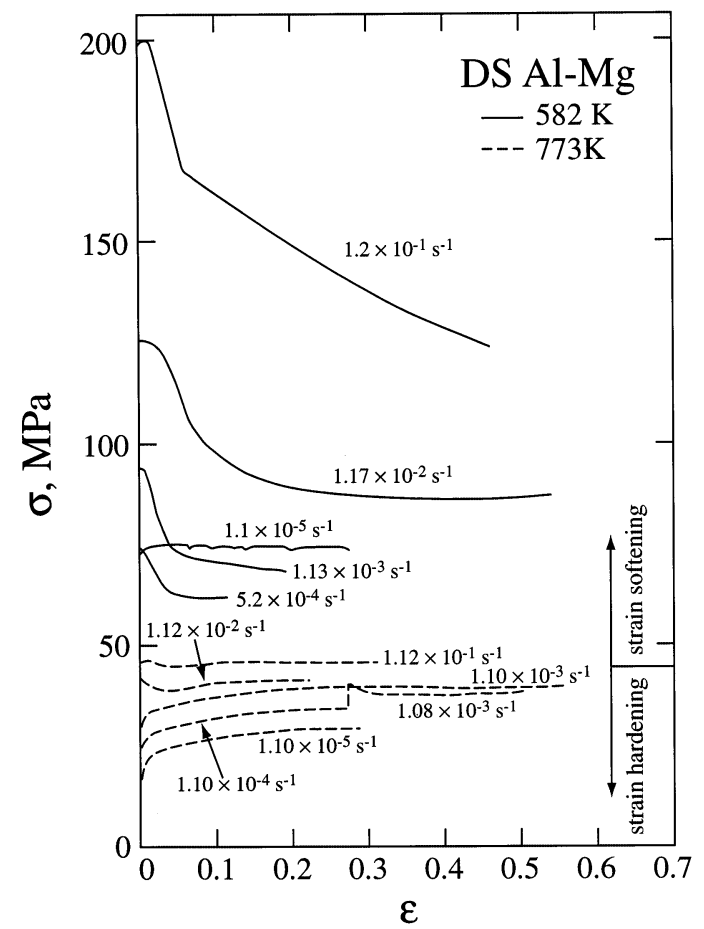

Fig. 6. The data of Oliver and Nix [27] for DS Al-Mg taken at constant strain rates are plotted as stress versus strain. Regions of strain hardening and strain softening is indicated.

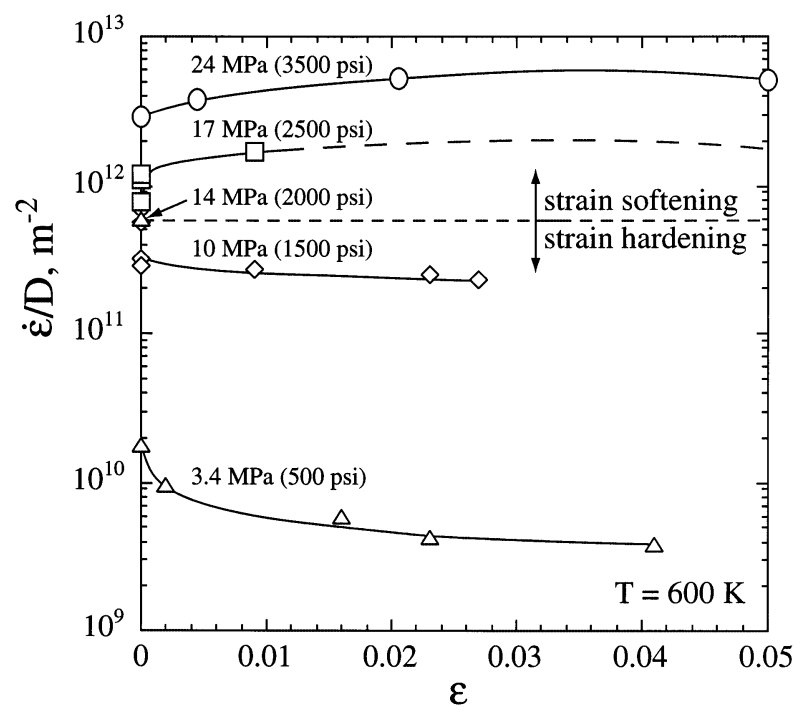

Fig. 7. Creep data from a low-impurity $\mathrm{Al}-2.1 \mathrm{Mg}$ [39] are plotted as diffusivity-compensated creep rate versus creep strain. Regions of strain hardening and strain softening is indicated. diffusion-compensated strain rate of $\approx 1 \times 10^{12} \mathrm{~m}^{-2}$ at $773 \mathrm{~K}$, where straining causes neither hardening nor softening. These trends are observed in pure $\mathrm{Al}-\mathrm{Mg}$ alloys $[2,39]$ and in commercial solid-solution alloys [38]. Fig. 7 shows the same trends in a pure $\mathrm{Al}-2.1 \mathrm{Mg}$ alloy creep tested at a number of constant stresses [39]. At the two highest stresses, the creep rate is seen to increase with the creep strain (strain softening). At the two lowest stresses, the creep rate is seen to decrease with the creep strain (strain hardening). The separation of the strain-softening region from the strain-hardening region in the pure $\mathrm{Al}-2.1 \mathrm{Mg}$ alloy is also found to occur at about the same value of $\dot{\varepsilon} / D_{\mathrm{L}}\left(6 \times 10^{11} \mathrm{~m}^{-2}\right)$ observed in the DS $\mathrm{Al}-\mathrm{Mg}$ alloy. The explanation of the strain hardening and strain softening regions is centered on solute-drag creep where the mobile dislocation density controls the creep rate. When the mobile dislocation density is low, the creep strength will be high. With creep straining, the dislocation density increases (dislocation multiplication) and the creep strength decreases (strain softening) until a steady-state structure is achieved. On the other hand, at low stresses, the initial mobile dislocation density is predicted to be higher than the equilibrium density of mobile dislocations for a given low creep stress. Hence, the initial dislocation density will be lowered by creep straining and the creep rate will decrease (strain hardening). The large strain softening seen in the DS Al$\mathrm{Mg}$ material at high stresses (Fig. 6) leads to a decrease in the flow stress until it becomes lower than the flow stress for dislocation-climb creep. In this way, dislocation-climb creep becomes the more difficult of the two sequential processes of glide and climb. Thus, the constant structure dislocation climb process $(n=8)$ becomes applicable, as seen in Fig. 5, at high stresses in the range of $\dot{\varepsilon} / D_{\mathrm{L}}=10^{13}$ to $10^{18} \mathrm{~m}^{-2}$. With a decrease in strain rate, however, the $\mathrm{DS} \mathrm{Al}-\mathrm{Mg}$ alloy reverts back to creep behavior of a Class I solute-drag material. This low stress region is described in the following paragraph.

The DS Al- $\mathrm{Mg}$ material shows an inverse strain-rate effect in the vicinity of the threshold stress at $582 \mathrm{~K}$, i.e. at $\sigma / E$ equal to $\approx 1 \times 10^{-3}$ (Fig. 5). Fig. 6 shows that the flow stress increases with a decrease in strain rate $\left(5.2 \times 10^{-4}\right.$ to $\left.1.1 \times 10^{-5} \mathrm{~s}^{-1}\right)$ at $582 \mathrm{~K}$. In addition, a serrated stress-strain curve is evident at a strain rate of $1.1 \times 10^{-5} \mathrm{~s}^{-1}$ when the temperature is $582 \mathrm{~K}$. These effects are observed at a diffusion-compensated strain rate, $\dot{\varepsilon} / D_{\mathrm{L}}$ of $\approx 1 \times 10^{12} \mathrm{~m}^{-2}$. This value of $\dot{\varepsilon} / D_{\mathrm{L}}$ is eight orders of magnitude lower than the value of $\dot{\varepsilon} / D_{\text {eff }}$ $\left(10^{20} \mathrm{~m}^{-2}\right)$ observed for the pure $\mathrm{Al}-\mathrm{Mg}$ alloys (Fig. 4). This difference can be partly attributed to the much lower mobile dislocation density in the $\mathrm{DS} \mathrm{Al}-\mathrm{Mg}$ than in the pure $\mathrm{Al}-\mathrm{Mg}$ alloys at their respective threshold stress regions. The low mobile dislocation density means that, at a given strain rate, the velocity of the 




Fig. 8. Creep data of high-purity nickel [2], fine-grained T-D nichrome [17], coarse-grained T-D nichrome [41,42] and single-crystal T-D nichrome [43] are presented. Diffusivity-compensated creep rate is plotted as a function of modulus-compensated stress.

dislocation is high $(\dot{\varepsilon} \propto v \rho b)$. A high dislocation velocity requires a high temperature before the magnesium solute atoms can move rapidly enough to interact continuously with the moving dislocations. Thus, the anomalous effects observed in pure $\mathrm{Al}-\mathrm{Mg}$ alloys at $0.31 T_{\mathrm{m}}$ do not appear until $\approx 0.8 T_{\mathrm{m}}$ for the dispersion-strengthened $\mathrm{Al}-\mathrm{Mg}$ material.

It is worth noting that threshold stresses became a new variable with the advent of new alloys prepared by powder metallurgy and mechanical alloying procedures, followed by thermal-mechanical working. This approach invariably introduces additional unanticipated impurities, not only with oxide formation but also with the introduction of new solute elements from the mechanical working of the powders with hard metal-based balls. Jansen and Dunand [40] have avoided this problem by preparing dispersion hardened $\mathrm{Al}-25 \mathrm{vol} . \% \mathrm{Al}$ through an ingot-metallurgy route. The aluminum was $99.9 \%$ pure. This material exhibited no threshold stress. The stress exponent was about eight and the material was stronger than the DS $\mathrm{Al}-\mathrm{Mg}$ material in Fig. 6, even at $723 \mathrm{~K}$. These results give added evidence that threshold stresses arise from solute interactions with dislocations. The particles simply control the temperature at which threshold stresses appear by controlling the mobile dislocation density.

\subsection{Creep of Class II solid solution alloys}

The creep of Class II solid solutions is by slip controlled by dislocation climb. The creep behavior of these solid solution alloys is usually easier to interpret than in creep of Class I solute drag controlled alloys. The factors influencing the high temperature strength are principally the self-diffusion coefficient, the elastic modulus, the stacking fault energy of the solid solution alloy and the barrier spacing to dislocation motion (the subgrain size or the particle spacing). An example is that of nickel and its alloys. Fig. 8 shows a plot of $\dot{\varepsilon} / D_{\mathrm{L}}$ as a function of $\sigma / E$ for polycrystalline nickel, nichrome $(\mathrm{Ni}-20 \mathrm{Cr})$, fine-grained $\mathrm{T}-\mathrm{D}$ nichrome and coarse-grained and single crystalline $\mathrm{T}-\mathrm{D}$ nichrome $[2,17,41-43]$. The stress exponent is equal to about five for both nickel and nichrome, in agreement with creep behavior of metals that develop subgrains and are controlled by lattice self diffusion. Both show powerlaw breakdown at $\dot{\varepsilon} / D_{\mathrm{L}}$ equal to $\approx 10^{13} \mathrm{~m}^{-2}$. The increase in strength of nickel with chromium addition is attributed to a stacking-fault energy effect. When nichrome is dispersed with thoria particles, known as $\mathrm{T}-\mathrm{D}$ nichrome, the material is made yet stronger and the stress exponent is eight for the fine-grained material. The higher stress exponent is that expected for creep under constant structure. The structure relates to a fixed dislocation substructure that is kept constant during creep by the presence of the inert particles of thoria. The T-D nichrome had a grain size of dimensions $30 \times 70 \mu \mathrm{m}$, giving it a grain aspect ratio (GAR) of 2:1 [17]. When this material was heat-treated to obtain a coarse grain size (annealed at $1343^{\circ} \mathrm{C}, 0.93$ $T / T_{\mathrm{m}}$ ), the creep resistance dramatically improved (Fig. 8 ). The grains were $\approx 100-300 \mu \mathrm{m}$ in size, with a GAR of three. The improvement in creep resistance is not a grain size effect. This is evident by the fact that singlecrystalline $\mathrm{T}-\mathrm{D}$ nichrome $[43,44]$ has exactly the same creep strength as the coarse-grained material.

The creep data for coarse-grained and single-crystalline $\mathrm{T}-\mathrm{D}$ nichrome reveal threshold-stress-type behavior (Fig. 8). The modulus-compensated threshold stress calculated to fit the $\mathrm{T}-\mathrm{D}$ nichrome data is $\approx 5 \times$ $10^{-4}[17,43]$. This value does not appear to fit with any specific dislocation mechanism. Whittenberger [45] studied the creep behavior of various nickel-base coarse-grained ODS alloys. He showed that the threshold stress increased from 1.9 to $3.7 \times 10^{-3} E$ with increase in the GAR. The present authors believe that the GAR correlation, together with the single crystal behavior, gives a hint on the mechanism leading to a threshold stress. It is proposed that it is the annealing (soaking) temperature that dictates the creep strength change and the presence of the threshold stress. High annealing temperatures promote the dissolution of all precipitates and accumulation of solute atoms in the 
matrix. The higher the annealing temperature and longer the annealing time, the higher the amount of solute atoms that will be created. The single crystal, if prepared by zone melting (not zone refining) techniques, would have had the highest amount of foreign elements in solution. It is concluded that the threshold stress in ODS nickel alloys occurs as a result of the interaction of the newly created migrating solute atoms with moving dislocations. One mystery that remains is the lack of a temperature-dependent threshold stress. A weak evaporation effect on the solute concentration at dislocation sites with an increase in temperature may contribute to the insensitivity of temperature on the threshold stress. These considerations lead to the conclusion that a high temperature annealed $\mathrm{T}-\mathrm{D}$ nichrome changes from a Class II solid solution alloy at high creep stresses to a Class I solid solution alloy at low stresses, just as with the DS Al-Mg alloy.

The pattern shown in Fig. 8 is observed in other dispersion-hardened nickel-base alloy systems [46-48]. Heilmaier et al. [47] evaluated the creep properties of PM 3030 (a Ni-17Cr-6Al-3.5W-2Mo-2Ta-1.1 $\mathrm{Y}_{2} \mathrm{O}_{3}$ alloy). The strength of $\mathrm{PM} 3030$ at $1000^{\circ} \mathrm{C}$ was enhanced by heat-treatment. The material was given a zone-annealing treatment (presumably with partial local melting occurring). The GAR was $>100$. The material exhibited a high apparent threshold stress of $\approx \sigma / E=8 \times 10^{-4}$. This high value of $\sigma / E$ can be related to the maximum amount of impurity atoms put in solution in the PM 3030 material by the special heat treatment. Soaking time at high temperature is also an important variable in influencing the creep rate. Greenfield et al. [49] showed that the creep rate of a Class I $\mathrm{Mg}-\mathrm{Zr}$ alloy containing zirconium hydride precipitates, tested at $400^{\circ} \mathrm{C}$, decreased with soaking time at $600^{\circ} \mathrm{C}$ prior to testing. As much as 1000 -fold decreases in creep were observed.

\section{Grain boundary sliding accommodated by slip}

Grain boundary sliding (GBS) occurs readily during creep of polycrystalline solids. The process of grain boundary sliding requires other accommodation processes to accompany it. Generally, dislocation generation and motion is the accommodation process for continued GBS within any given grain. Grain boundary migration often accompanies grain boundary sliding. When the grain size is fine, typically $<50 \mu \mathrm{m}$, creep by GBS can occur more readily than diffusion-controlled dislocation creep mechanisms, especially at low stresses. The stress exponent ranges from one to two and agrees well with a model based on GBS accommodated by slip developed by Ball and Hutchison [50]. The stress exponent is related to the accommodation process of dislocation motion involving the sequential processes of glide and climb of dislocations. When dislocation glide is rate-controlling the stress exponent is one. When dislocation climb is rate-controlling, a dislocation pileup stress is present and the stress exponent becomes two. Low stress exponents (high strain rate sensitivities) often lead to high elongations. Fine-grained metals and ceramics that exhibit high rate sensitivity and have high tensile elongations are known as superplastic materials. Generally, superplasticity is only observed at low strain rates because dislocation creep processes without GBS intervene at high strain rates. Recent activities have centered on developing materials that exhibit highstrain-rate superplasticity (HSRS). The success of HSRS was achieved when investigations were initiated on ultrafine grain size materials, with grain sizes ranging from 0.5 to $5 \mu \mathrm{m}$. HSRS in aluminum and its alloys was first observed by Nieh et al. [51] and subsequently extensively investigated by Higashi et al. [52]. The presence of a liquid phase at the grain boundary has proved to be an important contributor to enhancing HSRS [53]. The field of superplasticity and of grainboundary-sliding mechanisms in metals and ceramics is described by Nieh et al. [54].

The grain-size dependence of the creep rate for superplastic materials is found to follow $\dot{\varepsilon} \propto d^{-p}$, where $p=2$ when lattice-diffusion is the rate-controlling GBS process, and $p=3$ when grain-boundary diffusion is the rate-controlling GBS process $[55,56]$. A threshold stress is often observed for creep of fine-grained materials. The threshold stress for GBS creep has been the source of great debate and has remained mainly as an adjusting factor to obtain a stress exponent of two. Kim and Kum [57] have tabulated data of threshold stress for a number of superplastic materials, and have indicated that the grain size, temperature and melting temperature are variables.

It is proposed that the threshold stress for GBS creep should be the same as the threshold stress for dislocation creep in coarse-grained materials. This is because GBS creep is rate-controlled by the glide and climb of dislocations. Thus, both slip and GBS processes are rate-controlled by the same rate-controlling mechanism. A test of this hypotheses is made between the DS $\mathrm{Al}-\mathrm{Mg}$ material (Fig. 5) and a fine-grained superplastic $\mathrm{Al}-5 \mathrm{Mg}-1.2 \mathrm{Cr}$ alloy, where threshold stresses are also observed. Fig. 9 shows the creep behavior of a $3 \mu \mathrm{m}$ grain size $\mathrm{Al}-5 \mathrm{Mg}-1.2 \mathrm{Cr}$ material, plotted as $\dot{\varepsilon} / D_{\mathrm{L}}$ as a function of $\sigma / E$ [55]. The creep data for the $\mathrm{Al}-5 \mathrm{Mg}-$ $1.2 \mathrm{Cr}$ material are given as points for the five temperatures studied. The base line given as a dash-dot line is for coarse-grained $\mathrm{Al}-\mathrm{Mg}$ alloys and the base line for pure aluminum is given by a dashed line. The creep rate of the fine-grained material is seen to be higher than that for the pure $\mathrm{Al}-\mathrm{Mg}$ alloys and, in the extreme case, is almost as high as that observed for pure aluminum. The creep rate-stress relation of the $\mathrm{Al}-5 \mathrm{Mg}-$ 
1.2Cr material follows a stress exponent of about two, with clear evidence for a threshold stress that is a function of temperature. The threshold stress is seen to decrease with an increase in temperature, similar to that observed in the DS $\mathrm{Al}-\mathrm{Mg}$ material. At very low stresses, dislocation-climb creep processes become more facile and the stress exponent goes towards a slope of $\approx 4.5$. This is the same slope as that observed in the pure $\mathrm{Al}-\mathrm{Mg}$ alloys at low stresses [26].

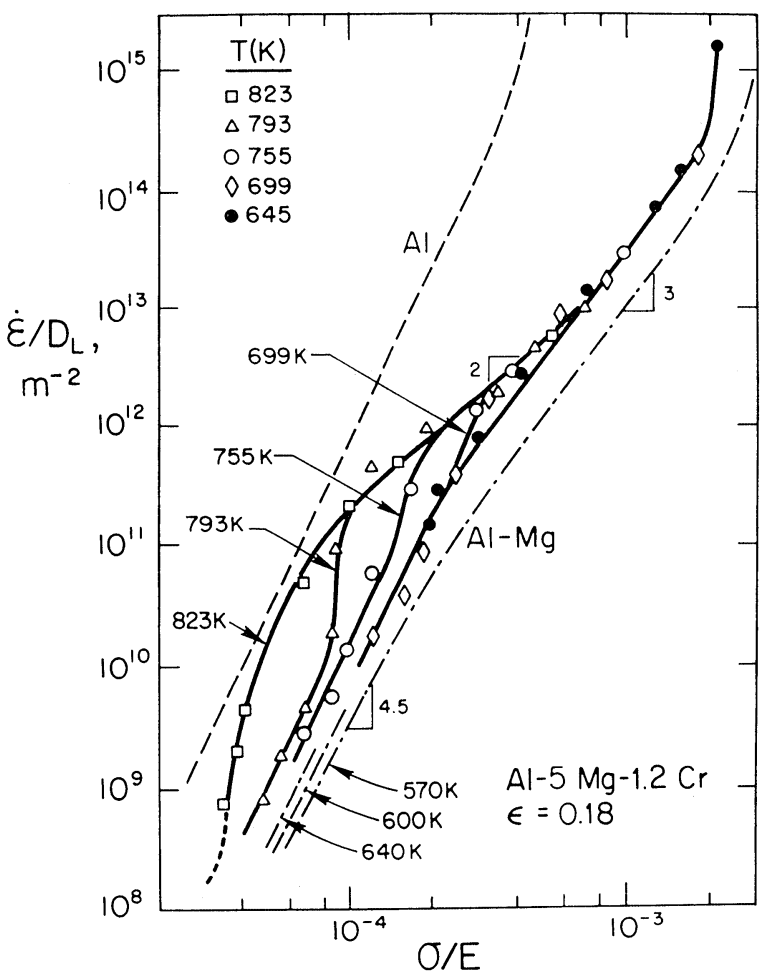

Fig. 9. Creep data from a fine-grained $(d=3 \mu \mathrm{m}) \mathrm{Al}-5 \mathrm{Mg}-1.2 \mathrm{Cr}$ [55] are presented as diffusivity-compensated creep rate as a function of modulus-compensated stress.

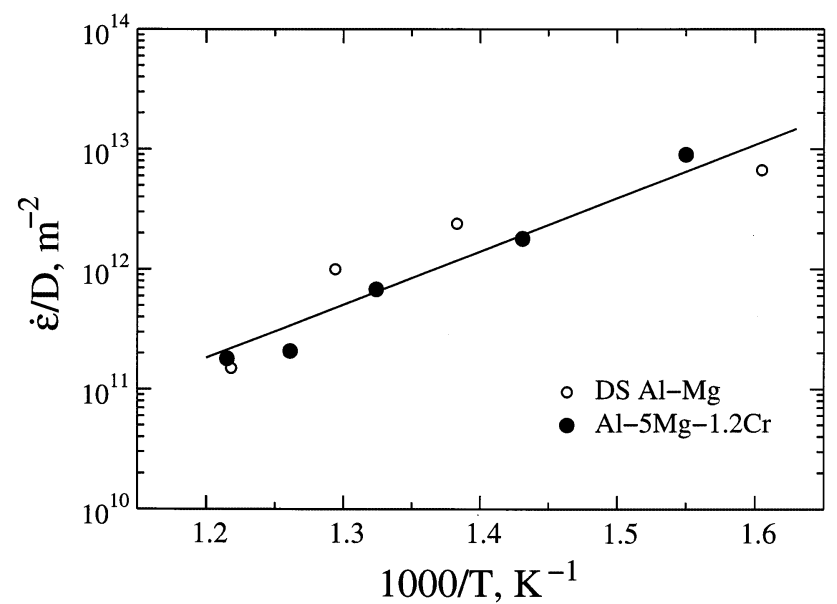

Fig. 10. Diffusivity-compensated creep rates corresponding to the onset of threshold-stress behavior in DS Al-Mg [27] and fine-grained $\mathrm{Al}-5 \mathrm{Mg}-1.2 \mathrm{Cr}$ [55] are plotted as a function of inverse absolute temperature.
Comparison of the threshold stresses obtained in GBS creep (Fig. 9) with the threshold stresses obtained in solute-drag dislocation creep (Fig. 5) reveal that similar values of the diffusion-compensated strain rate are observed. This observation would indicate that the threshold stress is best described as the threshold strain rate, or more accurately as 'threshold lattice-diffusioncompensated strain rate', $\dot{\varepsilon}^{*}=\left[\dot{\varepsilon} / D_{\mathrm{L}}\right]_{\text {threshold. }}$ Fig. 10 shows the logarithm of $\dot{\varepsilon}^{*}$ plotted as a function of reciprocal absolute temperature. The values of $\dot{\varepsilon}^{*}$ were determined by the separation of the extrapolated $n=2$ line from the experimental data for GBS (Fig. 9) and the intersection of the $n=8$ line (extrapolated) with the experimental data for slip creep (Fig. 5). It can be seen that the $\dot{\varepsilon}^{*}$ values for the fine-grained $\mathrm{Al}-5 \mathrm{Mg}-1.2 \mathrm{Cr}$ alloy virtually superimpose on the $\dot{\varepsilon}^{*}$ values for the DS $\mathrm{Al}-\mathrm{Mg}$ material. This result gives overwhelming support to GBS controlled by dislocation slip processes. A plot of $[\sigma / E]_{\text {threshold }}$ versus reciprocal temperature did not correlate well; this is because the stresses for the DS $\mathrm{Al}-\mathrm{Mg}$ are higher than for the fine-grained $\mathrm{Al}-5 \mathrm{Mg}-$ $1.2 \mathrm{Cr}$ material with dissimilar stress exponents.

\section{Summary and conclusions}

Diffusion-controlled-creep processes are used to assess the creep behavior of dispersion and solute-hardened materials at coarse and fine grain sizes. Deformation can be controlled either by dislocation creep (slip) or by grain boundary sliding accommodated by dislocation creep (GBS). When dislocation creep dominates deformation, the rate-controlling process is either by solute drag or by climb of dislocations. These materials exhibit power-law creep, with stress exponents of either three, five, eight or infinity (threshold stress). When grain-boundary sliding dominates deformation, the rate-controlling process is also either solute drag or climb of dislocations within each grain. These materials exhibit stress exponents of one or two.

The analyses in the present paper can be summarized as follows: (1) Stress-rupture data of typical advanced power-plant-ferritic steel has been analyzed by means of power law relations with stress exponents of eight, five and three. Stress-rupture data of ferritic steels that show a stress exponent of three can be expected to show a stress exponent of five at lower stresses. (2) Creep behavior of a dispersion-strengthened $\mathrm{Al}-\mathrm{Mg}$ alloy (DS $\mathrm{Al}-\mathrm{Mg}$ ) is similar to the creep behavior of pure $\mathrm{Al}-\mathrm{Mg}$ alloys. Both the pure $\mathrm{Al}-\mathrm{Mg}$ alloys and the $\mathrm{DS} \mathrm{Al}-\mathrm{Mg}$ material are Class I solid solution alloys, for which solute-drag creep is rate controlling. The DS $\mathrm{Al}-\mathrm{Mg}$ material and the pure $\mathrm{Al}-\mathrm{Mg}$ alloys show strain-softening behavior at high stresses and 
strain-hardening behavior at low stresses. Both show inverse strain-rate effects and serrated stress-strain curves. Both show threshold stress behavior. The difference in temperatures at which threshold stresses are observed is explained by a difference in the mobile dislocation density. There is a high mobile dislocation density for the pure $\mathrm{Al}-\mathrm{Mg}$ alloys and a low mobile density for the DS Al-Mg material because of the pinning effect of particles. At high temperature, the threshold stress decreases with an increase in temperature because the amount of solute at the dislocation site decreases as a result of an evaporation effect. (3) Quasi-superplastic behavior is observed in $\mathrm{Al}-\mathrm{Mg}$ alloys that have a stress exponent near three because the strain-rate-sensitivity exponent is relatively high. Addition of manganese or iron increases the stress exponent. Addition of zinc does not change the stress exponent of $\mathrm{Al}-\mathrm{Mg}$ alloys provided the magnesium content is $\approx 4 \mathrm{wt} . \%$. (4) Class II alloys are controlled by dislocation climb. Stress exponents of five and eight are observed. A stress exponent of five results from subgrain formation. When subgrains do not form during creep, the structure is unchanged with stress and a stress exponent of eight is obtained. The increase in strength of Class II alloys by solid solution alloying is a result of the decrease in stacking fault energy. (5) Threshold stresses are observed in dispersion-hardened Class II alloys. These arise from soaking the material at very high temperatures. High soaking temperature leads to dissolution of precipitates and the solute contributes to the creation of a threshold stress. The threshold stress is not a function of the temperature of creep testing, but of the temperature during prior processing. The stable solutes created during high-temperature processing do not evaporate from dislocation sites with an increase in testing temperature. (6) Grain boundary sliding accommodated by slip (designated as GBS) dominates the creep process when the grain size is fine. The deformation mechanism in superplastic metallic materials is GBS. High-strain-rate superplasticity (HSRS) results when the grain size is ultra fine. HSRS materials show threshold stresses The threshold stress arises from solute atom interactions with moving dislocations in the accommodation process of GBS and begins at a fixed value of the solute-diffusion-compensated strain rate, $\dot{\varepsilon} \div D_{\text {sol }}$. The threshold stress is more appropriately described as a threshold strain rate. The value of $\dot{\varepsilon} \div D_{\text {sol }}$ is shown to be a function of temperature and results in threshold stresses that are a function of temperature. The same value of $\dot{\varepsilon} \div D_{\text {sol }}$ for the start of the threshold stress is found for a finegrained $\mathrm{Al}-\mathrm{Mg}-\mathrm{Cr}$ alloy and for a $\mathrm{DS} \mathrm{Al}-\mathrm{Mg}$ material. This is evidence that GBS is accommodated by dislocation creep.

\section{Acknowledgements}

The authors acknowledge the continued close interaction of many colleagues over recent years that have helped the present authors to formulate many of the concepts presented in this paper. We especially thank Professors William Nix, Kenji Higashi, Woo-Jin Kim, and Dr Gaspar Gonzalez-Doncel, Dr Donald R. Lesuer, Dr T.G. Nieh, Dr Oscar A. Ruano, Dr Chol K. Syn and Dr Jeffrey Wadsworth. One author (EMT) acknowledges the support of the National Science Foundation under Grant No. DMR-9702156.

\section{References}

[1] J.C.M. Li, A.K. Mukherjee (Eds.), Rate Processes in Plastic Deformation of Materials - Proceedings of the John E. Dorn Symposium, Metals Park, OH, 1975.

[2] O.D. Sherby, P.M. Burke, Prog. Mater. Sci. 13 (1968) 325.

[3] J. Weertman, Trans. ASM 61 (1968) 681.

[4] A.K. Mukherjee, J.E. Bird, J.E. Dorn, Trans. ASM 62 (1969) 155.

[5] R.S. Mishra, A.K. Mukherjee, K. Linga-Murty (Eds.), Creep Behavior of Advanced Materials for the 21st Century - Proceedings of a Symposium, 28th February to 4th March, 1999, San Diego, CA, TMS, Warrendale, PA, 1999, pp. 391-493.

[6] O.A. Ruano, J. Wadsworth, O.D. Sherby, Acta Metall. 36 (1988) 1117.

[7] F.A. Mohamed, T.G. Ginter, Acta Metall. 30 (1982) 1869.

[8] M.Y. Wu, O.D. Sherby, Acta Metall. 32 (1984) 1561.

[9] J.N. Wang, Acta Metall. 44 (1996) 855.

[10] W. Blum, W. Maier, Phys. Stat. Sol. (a) 171 (1999) 467.

[11] T.G. Langdon, The interpretation of creep mechanisms in high temperature flow, in: E.M. Taleff, C.K. Syn, D.R. Lesuer (Eds.), Deformation, Processing and Properties of Structural Materials, TMS, Warrendale, PA, 2000, pp. 109-120 Proceedings of the Honorary Symposium for Professor Oleg D. Sherby, March 14-16, 2000.

[12] J. Weertman, Trans. AIME 218 (1960) 207.

[13] J. Weertman, J. Appl. Phys. 28 (1957) 362.

[14] D.R. Lesuer, C.K. Syn, O.D. Sherby, An evaluation of power law breakdown in metals, alloys, dispersion hardened materials, and compounds, in: E.M. Taleff, C.K. Syn, D.R. Lesuer (Eds.), Deformation, Processing and Properties of Structural Materials, TMS, Warrendale, PA, 2000, pp. 81-194 Proceedings of the Honorary Symposium for Professor Oleg D. Sherby, March 14-16, 2000.

[15] S.V. Raj, Scr. Metall. 20 (1986) 1333.

[16] O.D. Sherby, R.H. Klundt, A.K. Miller, Metall. Trans. 8A (1977) 843.

[17] J. Lin, O.D. Sherby, Res. Mech. 2 (1981) 251.

[18] R.S. Mishra, A.B. Pandey, Metall. Trans. A21 (1990) 2089.

[19] S.L. Robinson, O.D. Sherby, Acta Metall. 17 (1969) 109.

[20] T. Fujita, Adv. Mater. Proc. 157 (2000) 55.

[21] F.C. Monkman, N.J. Gran, Proc. ASTM 56 (1956) 593.

[22] H. Oikawa, Technology Reports, Tohoku University 47 (1982) 67.

[23] W. Koster, Z. Metallkunde 39 (1948) 1.

[24] C.G. Schmidt, C.M. Young, B. Walser, R.H. Klundt, O.D. Sherby, Metall. Trans. A13 (1982) 447.

[25] E.M. Taleff, P.J. Nevland, S.J. Yoon, The effect of ternary alloying additions on solute-drag creep in aluminum-magnesium alloys, in: E.M. Taleff, C.K. Syn, D.R. Lesuer (Eds.), Deforma- 
tion, Processing and Properties of Structural Materials, TMS, Warrendale, PA, 2000, pp. 373-384 Proceedings of the Honorary Symposium for Professor Oleg D. Sherby, March 14-16, 2000.

[26] H. Oikawa, H. Sato, K. Maruyama, Mater. Sci. Eng. 75 (1985) 21.

[27] W.C. Oliver, W.D. Nix, Acta Metall. 30 (1982) 1335.

[28] T.R. McNelley, D.J. Michel, A. Salama, Scr. Metall. 23 (1989) 1657.

[29] M.J. Mills, J.C. Gibeling, W.D. Nix, Acta Metall. 33 (1985) 1503.

[30] K. Kimura, H. Kushima, F. Abe, K. Yagi, Inherent creep strength and a new approach to the evaluation of long term creep strength properties, in: J.C. Earthman, F.A. Mohamed (Eds.), Creep and Fracture of Engineering Materials and Structures, TMS, Warrendale, PA, 1997, pp. 89-98 Proceedings of the Seventh International Conference held at the University of California, Irvine, August 10-15, 1997.

[31] H. Luthy, A.K. Miller, O.D. Sherby, Acta Metall. 28 (1979) 169.

[32] N.R. Borch, L.A. Shepard, O.D. Sherby, Trans. ASM 52 (1960) 494.

[33] O.D. Sherby, R.A. Anderson, J.E. Dorn, Trans. AIME 191 (1951) 643.

[34] T. Hasegawa, T. Miura, T. Takahasi, T. Yakou, ISIJ Int. 32 (1992) 902.

[35] O.D. Sherby, G. Gonzalez-Doncel, O.A. Ruano, Threshold stresses in particle-hardened materials, in: J.C. Earthman, F.A. Mohamed (Eds.), Creep and Fracture of Engineering Materials and Structures, TMS, Warrendale, PA, 1997, pp. 9-18 Proceedings of the Seventh International Conference held at the University of California, Irvine, August 10-15, 1997.

[36] G. Gonzalez-Doncel, O.D. Sherby, Acta Metall. 41 (1993) 2797.

[37] R.W. Cahn, Grain boundary structures and impurities, in: Impurities and Imperfections, American Society for Metals, Cleveland, OH, 1955, pp. 41-83.

[38] C. Antes, U. Schmidt, O. Vohringer, D. Lohe, U. Muhle, U. Martin, H. Oettel, Deformation behavior and development of microstructure during creep of the superalloy CoCr22Ni22W14, in: J.C. Earthman, F.A. Mohamed (Eds.), Creep and Fracture of Engineering Materials and Structures, TMS, Warrendale, PA, 1997, pp. 99-108 Proceedings of the Seventh International Conference held at the University of California, Irvine, August $10-15,1997$

[39] O.D. Sherby, T.A. Trozera, J.E. Dorn, Proc. ASTM 56 (1956) 789.

[40] A.M. Jansen, D.C. Dunand, Acta Mater. 45 (1997) 4583.

[41] J. Weertman, P. Shahinian, J. Met. 10 (1956) 1223.

[42] P. Shanhinian, M.R. Achter, Trans. ASM 51 (1959) 244.

[43] R.W. Lund, W.D. Nix, Metall. Trans. 6A (1975) 1329.

[44] R.D. Kane, L.J. Ebert, Met. Trans. 7A (1976) 133.

[45] J.D. Whittenberger, Met. Trans. 7A (1976) 611.

[46] B. Wilshire, Creep processes in dispersion-strengthened alloys, in: E.M. Taleff, C.K. Syn, D.R. Lesuer (Eds.), Deformation,
Processing and Properties of Structural Materials, TMS, Warrendale, PA, 2000, pp. 195-206 Proceedings of the Honorary Symposium for Professor Oleg D. Sherby, March 14-16, 2000.

[47] M. Heilmaier, M. Nganbe, F.E.H. Miller, On the creep and superplastic behavior of the ODS nickel-based superalloy PM3030, in: E.M. Taleff, C.K. Syn, D.R. Lesuer (Eds.), Deformation, Processing and Properties of Structural Materials, TMS, Warrendale, PA, 2000, pp. 287-298 Proceedings of the Honorary Symposium for Professor Oleg D. Sherby, March 14-16, 2000.

[48] M. Heilmaier, B. Reppich, Assesing the HAI-model and the composite model of high temperature creep for solid solution nickel-base alloy, in: J.C. Earthman, F.A. Mohamed (Eds.), Creep and Fracture of Engineering Materials and Structures, TMS, Warrendale, PA, 1997, pp. 39-48 Proceedings of the Seventh International Conference held at the University of California, Irvine, August 10-15, 1997.

[49] P. Greenfield, C.C. Smith, A.M. Taylor, Trans. AIME 221 (1961) 1065.

[50] A. Ball, M.M. Hutchison, Met. Sci. J. 3 (1969) 1.

[51] T.G. Nieh, C.H. Henshall, J. Wadsworth, Scr. Metall. 18 (1984) 1405.

[52] K. Higashi, Overview of positive exponent superplasticity, in: E.M. Taleff, C.K. Syn, D.R. Lesuer (Eds.), Deformation, Processing and Properties of Structural Materials, TMS, Warrendale, PA, 2000, pp. 319-332 Proceedings of the Honorary Symposium for Professor Oleg D. Sherby, March 14-16, 2000.

[53] T.G. Nieh, J. Wadsworth, Mater. Sci. For. 233-234 (1997) 383.

[54] T.G. Nieh, J. Wadsworth, O.D. Sherby, Superplasticity in Metals and Ceramics, Cambridge University Press, Cambridge, UK, 1997.

[55] O.D. Sherby, J. Wadsworth, Prog. Mater. Sci. 33 (1989) 169.

[56] O.D. Sherby, J. Wadsworth, Mater. Sci. For. 233-234 (1997) 125.

[57] W.J. Kim, D.W. Kum, The effect of grain size on the threshold stress for superplastic flow in aluminum alloys, in: E.M. Taleff, C.K. Syn, D.R. Lesuer (Eds.), Deformation, Processing and Properties of Structural Materials, TMS, Warrendale, PA, 2000, pp. 353-361 Proceedings of the Honorary Symposium for Professor Oleg D. Sherby, March 14-16, 2000.

[58] I.S. Servi, N.J. Grant, Trans. AIME 191 (1951) 909.

[59] R. Horiuchi, M. Otsuka, Trans. JIM 13 (1972) 284.

[60] H. Oikawa, N. Matsuno, S. Karashima, Met. Sci. 9 (1975) 209.

[61] H. Oikawa, K. Sugawara, S. Karashima, Trans. JIM 19 (1978) 611.

[62] P. Yavari, T.G. Langdon, Acta Metall. 30 (1982) 2181.

[63] E.M. Taleff, G.A. Henshall, T.G. Nieh, D.R. Lesuer, J. Wadsworth, Metall. Mater. Trans. 29A (1988) 1081.

[64] E.M. Taleff, P.J. Nevland, P.E. Krajewski, Solute-drag creep and tensile ductility in aluminum alloys, in: R.S. Mishra, A.K. Mukherjee, K.L. Murty (Eds.), Creep Behavior of Advanced Materials for the 21st Century, TMS, Warrendale, PA, 1999, pp. $349-358$. 